National Science Foundation

\section{Grant applications go paperless}

Washington

EXPRES, the National Science Foundation (NSF)'s plan to make grant application all electronic, will take off at the end of this month. NSF hopes the project will streamline its review process and serve as a prototype for the exchange of scientific information between different computer environments. But success depends largely on factors outside NSF's control.

Formally titled Experimental Research in Electronic Submission, EXPRES

\section{Eucalyptus clean-up}

\section{New Delhi}

INDIA's northern state of Haryana appears to have found one solution for a major problem of developing countries - how to dispose of sewage cheaply. A five-year project at the Central Soil and Salinity Research Institute (CSSRI) at Karnal has revealed that untreated sewage is just the thing to encourage eucalyptus forests to grow on wasteland.

When the CSSRI scientists began their project back in 1981 , they simply pumped sewage into trenches on wasteland and planted eucalyptus trees on ridges between them. Now the wastelands have turned into eucalyptus forests, previously used sewage ponds have disappeared and there a fewer mosquitoes.

"Land disposal of sewage is the cheapest and most cost-effective method of disposing of urban waste waters as it utilizes the entire biosystem - soil and vegetation as a living filter", says Dr Ranbir Chabbra, a senior soil scientist at CSSRI. Untreated sewage contains large quantities of plant nutrients but the presence of pathogens, heavy metals, pesticides and above all its odour makes it unsuitable for growing agricultural crops and vegetables. But these considerations do not affect its use for growing trees which are used as timber and fuel but not as food, says Chabbra. As the trees act as biopumps, they prevent water-logging and thus groundwater pollution.

There are two reasons why the eucalyptus system is particularly attractive to the Haryana towns. First, CSSRI has shown that one hectare of eucalyptus irrigated by sewage water can earn the municipalities a gross return of $R s \mathbf{9 , 7 0 0}(\boldsymbol{£ 6 0 0}$ ) in the first year and $R s 28,000(£ 1,800)$ in the second year. The sludge accumulating in the furrows, which can be sold as manure, is a bonus. Second, the technology raises the prospects of developing plantations into green belts and scenic parks. No wonder the project has the approval of the state forest department as well as the pollution control board.

K.S. Jayaraman would shift proposal development, submission and review from reams of paper to the realm of computer workstations, so that a proposal could be distributed from its origin to NSF, and from NSF to reviewers, entirely by electronic transmission. Because the grant-seeking community is both technologically and geographically diverse, NSF thinks the scheme makes the perfect guinea pig for research on information exchange. The foundation receives ten copies each of 37,000 proposals from about 2,400 organizations in an average year.

The inspiration for EXPRES came from the NSF office that processes grant proposals, and gained impetus when Erich Bloch, a former vice-president at IBM, became NSF director in 1984. The foundation expects to announce two award recipients in September, and has earmarked \$2 million for EXPRES in fiscal year 1987 .

Although the duration of the awards is three years, funding for the remaining two is not "set in concrete". Competition for the awards may be keen nonetheless: an interest meeting last month drew more than 30 people, and nearly 200 organizations have requested project solicitations.

Part of the reason that EXPRES has sparked this response has to do with its applicability beyond the paper-shuffling procedure at NSF; as project manager Alvin Thaler claims, "the grant process is just a handle to grab hold of the whole problem of communicating scientific information". Ultimately, however, the project's implementation depends upon concurrent developments in computer standardization to lay the groundwork for open information exchange. EXPRES pilot installations will intially use NSFNET, a network that links the foundation's supercomputers and is itself still in its formative years. Although NSFNET currently conforms to DARPA protocol (a system developed by the Department of Defense), it will eventually adopt the universal Open Systems Interconnection (OSI) standards of the International Standards Organization. But OSI standards are also in their infancy, putting another question mark in the EXPRES timetable.

The birth of EXPRES, therefore, needs to be closely attended by the groups responsible for computer standards, such as the National Bureau of Standards and the American National Standards Institute.

The project may also have an ally in the Virginia-based Corporation for Open Systems (COS), an organization conceived just last year to accelerate implementation of OSI by coordinating industry efforts towards standardization. With $55 \mathrm{mem}$ bers, including IBM, AT\&T and Digital Equipment Corporation, COS could hasten the industry-wide compliance that NSF needs to make EXPRES operable. The view from COS is clear: programme manager Vance Mall says that if all concerned parties pool their efforts, EXPRES could be up and running by 1990.

Karen Wright

\section{Vane back to basics}

Wiтн the financial backing of Glaxo, the British pharmaceutical company, Sir John Vane is going back to his pharmacological roots, a year after leaving the Wellcome Foundation, of which he was research director.

Vane will direct the new William Harvey Research Institute at St Bartholomew's Hospital Medical College, situated close to

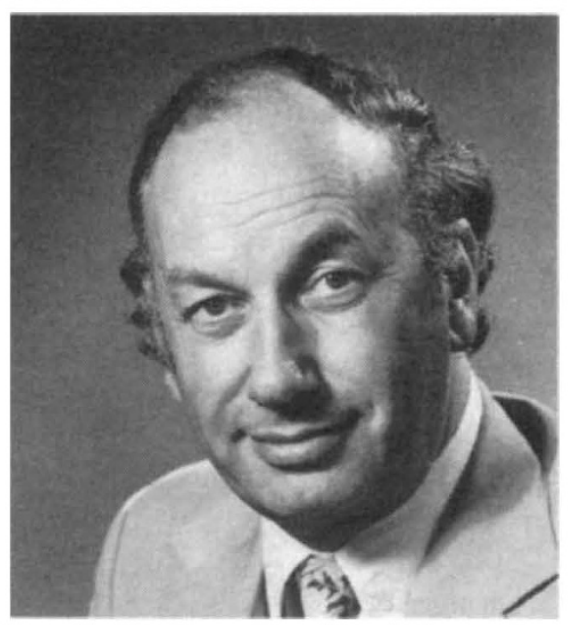

St Bartholomew's Hospital, where William Harvey established that blood circulates, but even closer to Smithfield, London's central meat market. Funds will be available for about a dozen scientists plus support staff for at least five years to carry out research on cardiovascular disease, with particular emphasis on atherosclerosis and eicosanoids, the area of research for which Sir John shared the 1982 Nobel prize for Physiology or Medicine.

The first of Vane's priorities is to stock the institute with Watenabe rabbits or other animal models of human atherosclerosis. With these and with the aid of cell culture and his own cascade bioassay system, Vane intends to improve the understanding of the pharmacology of cardiovascular disease. Against the trend, he has no plan to use the techniques of molecular genetics in the institute's research.

In return for financing the new institute, Glaxo has first rights on any discovery of commercial interest to it. Sir John is the second top Wellcome researcher to be snapped up by Glaxo; earlier this year, $\mathrm{Dr}$ Pedro Cuatrecasas left his position as head of research at Burroughs Wellcome, the US subsidiary of Wellcome plc, to set up a US research operation for Glaxo Ltd.

Peter Newmark 